\title{
EXCISION OF THE CENTRAL PHYSEAL BAR: A MODIFICATION OF LANGENSKIÖLD'S PROCEDURE
}

\section{ANDREW M. JACKSON}

In the growing child a central bone bridge fusing epiphysis to metaphysis will lead to progressive shortening and deformity. Provided that its size does not exceed half the cross-sectional area of the physis normal growth can be restored by resecting the bridge, and filling the defect with fat (Langenskiöld 1981; Peterson 1984). Furthermore, as growth resumes, minor deformities will correct spontaneously. Accurate mapping of the defect and operative planning are the keys to the success of this difficult surgery and biplanar tomograms or oblique CT scans are most helpful. The conventional surgical approach is through a metaphyseal window. Considerable stereotactic skill is required and there may be difficulties with irrigation, suction, illumination, magnification, and introducing dental mirrors and cutting instruments. The use of the arthroscope has recently been advocated in this context (Stricker 1992).

Operative technique. A modified approach was developed

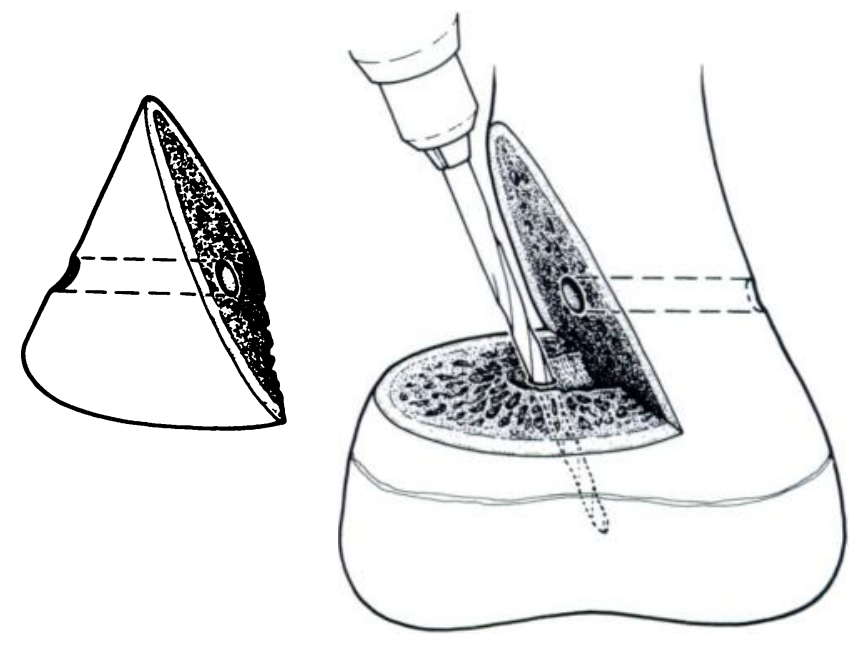

Fig. 1

Diagram to show the operative procedure.

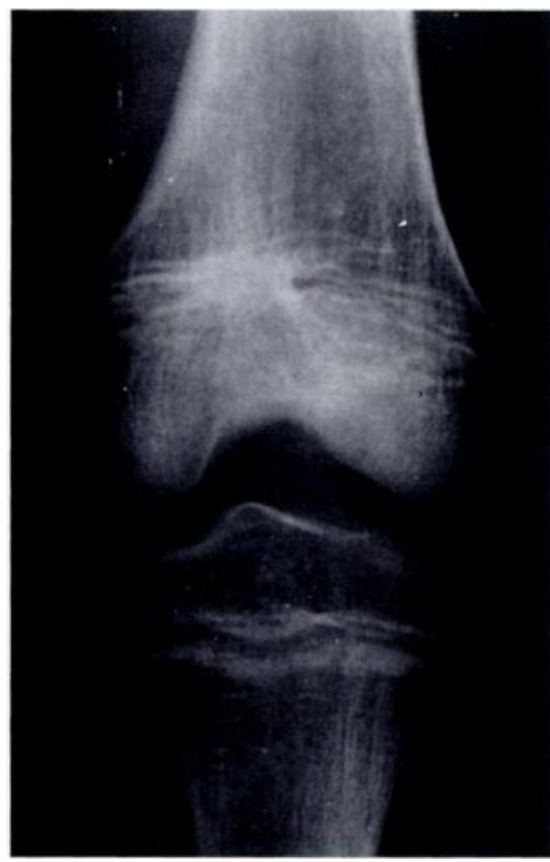

Fig. 2a

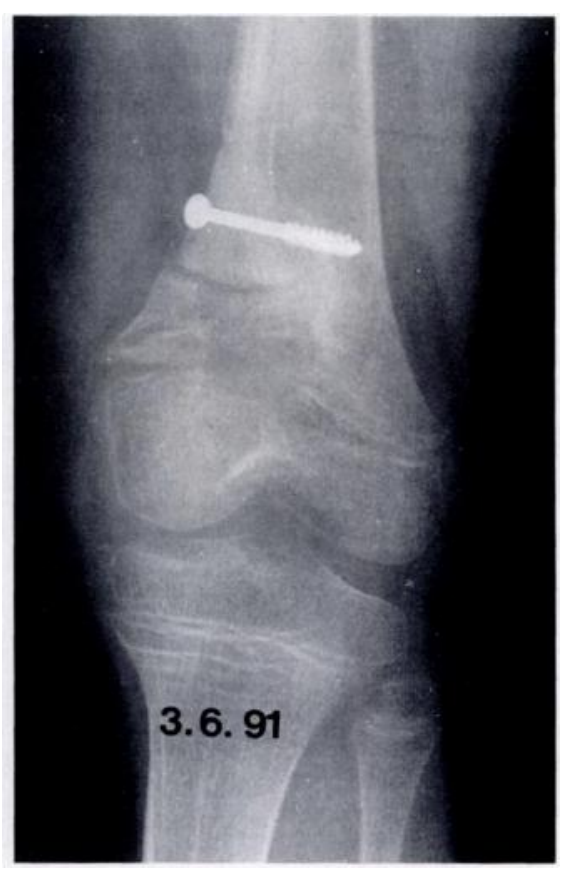

Fig. 2b

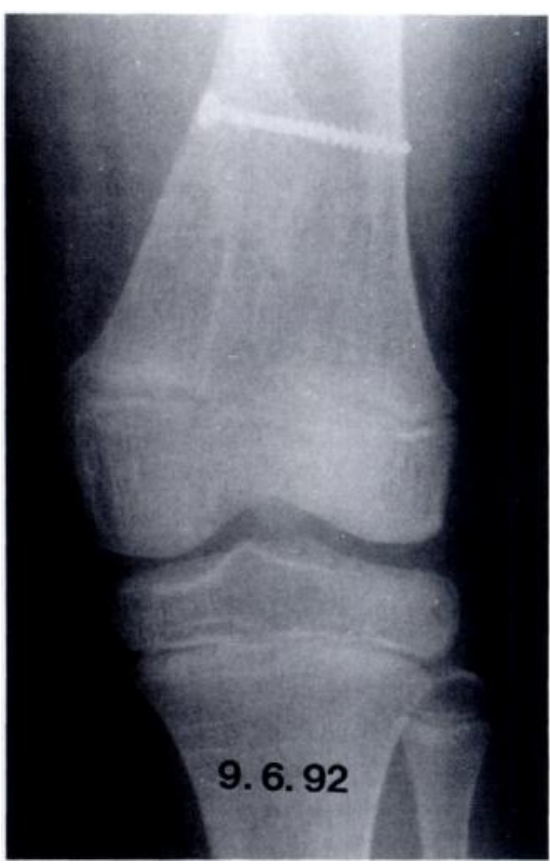

Fig. 2c

Figure $2 a-$ Central bone bridge in the physis of a seven-year-old girl. Figure $2 b-$ Two months postoperatively. Figure $2 c-$ Fourteen months postoperatively. The bone bridge has not recurred, the physis appears to have regenerated, and the deformity has corrected spontaneously.

A. M. Jackson, FRCS, Consultant Orthopaedic Surgeon Queen Mary's University Hospital, Roehampton Lane, London SW15 SPN, UK.

C1993 British Editorial Society of Bone and Joint Surgery $0301-620 \mathrm{X} / 93 / 4 \mathrm{R} 80 \$ 2.00$

J Bone Joint Surg [Br] 1993; 75-B:664-5.

Received 8 October 1992; Accepted 7 December 1992 in which a predrilled wedge of metaphysis is resected. The important horizontal cut is made 5 to $10 \mathrm{~mm}$ from the physis and parallel to it using the image intensifier and taking care not to damage the perichondrial ring. A tail of endosteal scarring, which extends into the metaphysis in such cases, is clearly seen on the horizontal 
cut surface, and is an accurate guide to the position of the underlying bone bridge (Fig. 1). Using this sclerotic bone as a landmark, a $4.5 \mathrm{~mm}$ drill can be passed with confidence through the substance of the bone bridge into the epiphysis again using the image intensifier to check the depth (Fig. 1). This hole is then expanded using a high-speed burr until the white of the physis is seen on all sides.

Case report. This method was used in a seven-year-old girl who had suffered neonatal staphylococcal septicaemia. An abnormality of the knee was first noticed at the age of two years, and by seven years there was a $10^{\circ}$ varus/recurvatum deformity and $2.5 \mathrm{~cm}$ of shortening (Fig. 2a). The predicted shortening at maturity would have been about $10 \mathrm{~cm}$.

After the bridge resection, a locally harvested free fat graft was used to fill the defect. By screwing the bone wedge back on top of it the fat graft was fixed and could not be displaced by haematoma, reducing the risk of recurrence of the bone bridge (Fig. 2b). By 15 months, the deformity had corrected, the lower femur had grown more than $2 \mathrm{~cm}$, and there was a slight decrease in the leg-length discrepancy (Fig. 2c).

Discussion. The correction of the deformity may be due, in part, to the fact that the physis was approached from the concavity of the deformity, and that the periosteum was stripped on only one side of the femur.
The main advantage of this method is that it affords good access and it is therefore less dependent on epiphyseal mapping. The replaced wedge of bone locks the free fat graft in place, and, since there is no residual cortical defect, the risk of postoperative fracture, to which some authors refer (Foster 1991) is reduced. The screw acts as a useful marker for the measurement of subsequent growth.

There may be a small risk of intraoperative fracture, but this is unlikely if the limb is correctly supported throughout the operation.

I wish to thank Mr Alan Gardner for referring this patient for treatment.

No benefits in any form have been received or will be received from a commercial party related directly or indirectly to the subject of this article.

\section{REFERENCES}

Foster BK. The experimental basis for growth plate surgery. In: Menelaus MB, ed. The management of limb inequality. Edinburgh, etc: Churchill Livingstone, $1991: 109-20$.

Langenskiöld A. Surgical treatment of partial closure of the growth plate. J Pediatr Orthop $1981 ; 1: 3-11$.

Peterson HA. Partial growth plate arrest and its treatment. $J$ Pediatr Orthop 1984; $4: 246-58$.

Stricker S. Arthroscopic visualization during excision of a central physeal bar. J Pediatr Orthop 1992; 12:544-6.

\section{CORRECTION}

Kristensen O, Nafei A, Kjaersgaard-Andersen P, Hvid I, Jensen J. Longterm results of total condylar knee arthroplasty in rheumatoid arthritis.

J Bone Joint Surg [ Br] 1992; 74-B:803-6.

On page 804, Table III was printed with the correct numbers in the body of the table, but incorrect percentages for the ranges of motion (ROM). The amended version is printed below.

Table III. Distribution of 64 knees according to range of motion (ROM), preoperatively and at follow-up. Figures in italics represent functionally acceptable range of motion

\begin{tabular}{|c|c|c|c|c|c|}
\hline \multirow[b]{2}{*}{ Preoperative } & \multirow[b]{2}{*}{ ROM } & \multicolumn{4}{|c|}{ ROM at follow-up } \\
\hline & & $\begin{array}{l}<60^{\circ} \\
2 \%\end{array}$ & $\begin{array}{l}60^{\circ} \text { to } 94^{\circ} \\
44 \%\end{array}$ & $\begin{array}{l}95^{\circ} \text { to } 104^{\circ} \\
33 \%\end{array}$ & $\underset{22 \%}{>105^{\circ}}$ \\
\hline $\begin{array}{l}<60^{\circ} \\
60^{\circ} \text { to } 94^{\circ} \\
95^{\circ} \text { to } 104^{\circ} \\
>105^{\circ}\end{array}$ & $\begin{array}{l}19 \% \\
42 \% \\
19 \% \\
20 \%\end{array}$ & $\begin{array}{l}0 \\
0 \\
1 \\
0\end{array}$ & $\begin{array}{r}7 \\
12 \\
6 \\
3\end{array}$ & $\begin{array}{r}4 \\
11 \\
1 \\
5\end{array}$ & $\begin{array}{l}1 \\
4 \\
4 \\
5\end{array}$ \\
\hline
\end{tabular}

